\title{
Factors Affecting Time Overrun in Construction Projects in Bhutan
}

\author{
Yeshi Tshering Sangay Wangmo Rigzin Choden \\ Civil Engineering and Architecture Department, College of Science and Technology, Royal University of \\ Bhutan \\ Tshewang Lhendup \\ Centre for Renewable and Sustainable Energy Development, Electrical Engineering Department \\ College of Science and Technology, Royal University of Bhutan, Rinchending, Bhutan \\ E-mail of the corresponding author: tshewanglhendup.cst@rub.edu.bt
}

\begin{abstract}
The construction industry has a significant influence on the economy of a country as it plays a vital role in its development. However, construction projects in countries usually faced time and cost overrun, affecting the economic development and overall performance of the contractors. As infrastructure development is one of the key activities in developing countries, it is very important to analyze the factors contributing to time overrun to enable effective contract management. Time overruns are always associated with cost overrun often putting burden to country's capital resources. Although time overruns have been recurring issues in construction industry, very little or no researches have been carried out in Bhutan so far. This paper presents a case study of time overrun of construction projects in Bhutan. The study was carried out through an online questionnaire consisting of thirtyone factors which are further sub-divided into seven categories. The one hundred twenty responses were analyzed using relative importance index which shows that inexperienced and financial instability of the contractor, incompetence of human resources, shortage and inefficient equipment, lack of construction materials are significant factors affecting time overrun. Issues related to sub-contracting, unrealistic calculation of the project duration, delay in the mobilization of machines are minor factors of time over-run of the construction projects in Bhutan.
\end{abstract}

Keywords: Time overrun, principle factors, factor analysis, adversity, average index.s

DOI: $10.7176 / \mathrm{JEP} / 11-29-01$

Publication date:October $31^{\text {st }} 2020$

\section{Introduction}

The construction industry is one of the key contributing sectors to Bhutan's economy. It constituted $15.87 \%$ of the GDP in 2017 and $16.28 \%$ in 2018 (NSB, 2018). This contribution to the economy is further added by the construction industry's potential to improve people's livelihood (CDB, 2019). However, infrastructure that connects people, ease the livelihoods and are the growth of development that has the potential to change the lives of communities at home are behind schedule and often miss deadlines (Kuensel, 2017). The construction process is a complex undertaking that involves different activities and stakeholders from initial planning through to the execution. Building a significant construction project without experiencing schedule delays and cost overruns is often the exception (Subramani, Prabhu, \& Dey, 2016).

Time overrun is generally defined as the difference between the estimated project duration and the actual time taken to complete the project. Time overrun occurs in most construction projects, and the magnitude of these delays varies considerably from project to project. The factors and the importance level reported were found to vary both from one region to another and from one country to other (Herrera, Sánchez, Castañeda, \& Porras, 2020). Many factors contribute to time overrun, the lack of experience and financial stability of the contractors in the project field are the leading factors. It is known that with the delay in work progress, the cost of the construction project will increase with detrimental effect on the quality of construction. Some of the factors that causes time overrun in a construction project are shortage of human resources, lack and efficiency of the equipment, and shortage of construction materials. The key stakeholders involved for the time extension are the contractors, owners, engineers, and sub-contractors. Hence, identifying the very source and significant reason for the time overrun in the construction project is important. Identifying and providing a proper solution to these factors will help to enhance the effective management and the administration of the contract time. Time is one of the key variables used to measure the performance of the projects. The negative effect of time overrun is not limited just to the construction sector, but the influence on the cost, quality, and the overall economy of the country.

Time overrun in construction is one of the most recurring issues and has an adverse effect on time, cost, quality, and safety of the project (Ozcan-Deniz, Zhu, \& Ceron, 2012). Subramani, Prabhu, and Dey (2016) identified that low labor productivity, design factors, and finding the frequency of the response are the most influencing factor causing time overrun in projects. On the other hand, Faridi and Sayegh (2006) found out that 
shortage of resources, shortage of human resources, the productivity of workforce and skills of the workforce are the major factors leading to delay in construction. However, proper schedule between contractor and consultant for preparation, submission, and approval of drawings and better human resources management can help improve labor skills and productivity.

Kamling, Olomolaiye, Holt and Harris (1997) defines time overrun as the extension of time beyond planned completion date traceable to the contractor. Researchers pointed out that incidents such as weather delays, unavailability of resources, design delays, and many more are the incidents that affect the project progress and postpone project activities. Pai and Bharat (2013) conducted a survey on different types of construction projects in Saudi Arabia to determine the causes of delay and its importance according to each of the project participants. The authors reported 73 causes of delay and noted that $70 \%$ of the projects have experienced time overrun. According to the survey, $76 \%$ of the contractors and $56 \%$ of the consultants stated that the average time overrun is between $10 \%$ and $30 \%$ of the original duration.

Researchers found out that improper planning and lack of communication lead to time overrun in the construction industry of Nigeria (Mohammed, 2012). Similarly, Doloi, Sawhney, Iyer and Rentala (2012), mentioned that lack of commitment, inefficient site management, poor site coordination, improper planning, lack of clarity in project scope, lack of communication, substandard contract, a slow decision from the owner, poor labor productivity, architects' reluctance for change and rework due to mistakes in construction causes a delay in the progress in as per the survey conducted in Indian construction projects.

Memon (2014) investigated the industry of construction of Malaysia with a total of 175 completed questionnaire sets. Frequent design changes, change in the scope of the project, financial difficulties of the owner, delays in decision making, and unforeseen ground conditions were the factors causing project delays as per the analysis of the investigation. Murali and Kumar (2019) concluded the survey pointing out that material management, site conditions, unskilled labor strikes, contractor financial difficulties, machines, and equipment difficulties delayed the progress of the project. On the contrary, as per the survey, problems in-ground anchoring projects, project execution requirements, and project management techniques of planning, directing, controlling, monitoring, procedures should be maintained to avoid the time overrun. Ubani, Okorocha and Emeribe (2013) concluded that contractors should be aware of the construction materials and are advised to purchase the right quantity and quality at the right time to avoid shortage and durability of materials.

Bhutan has seen a rise in infrastructure development projects in the last few decades. It also means, with the increase in the number of construction projects, the completed projects were mostly delayed or else time over-run projects. Time overrun in public sector construction in Bhutan has reached 64.53\% in the financial year 2016-2017 and $52.22 \%$ in the fiscal year 2017-2018 (CDB, 2018). This study was carried out to highlight the factors affecting time overrun in construction projects in Bhutan. The outcomes of the research are envisaged to help the contractors and clients to concentrate and enhance the effective management of resources, time, and quality by identifying the frequency and the severity of the factors.

\section{Methodology}

An online survey was conducted to find the factors causing time overrun in the construction projects in Bhutan. The questionnaire consists of 31 factors categorised into seven sections: (i) Project related; (ii) Project management team related; (iii) Contractor related; (iv) Labour related; (v) Equipment related; (vi) Material related, and (vii) Others. The respondents comprised chief engineers, executive engineers, assistant engineers, and junior engineers working in the private sector, corporations, and government agencies in different parts of the country.

A total of 120 responses were received out of which $41 \%$ were from the private construction companies, and $59 \%$ from the government agencies. Table 1 shows the detail of respondents and their backgrounds. The majority of respondents were assistant/junior/site engineers with less than five years of experience, which is due to the nature of the field where the actual execution of the projects is being carried out by the officials at these levels.

Table 1. Category of the Respondents

\begin{tabular}{|l|l|c|}
\hline \multirow{2}{*}{ Category } & \multicolumn{1}{|c|}{ Classification } & Number of respondents \\
\hline \multirow{2}{*}{ Organisation } & Private firm/Construction Company & 49 \\
\cline { 2 - 3 } & Client/Government Agency & 71 \\
\hline \multirow{2}{*}{$\begin{array}{l}\text { Academic } \\
\text { Qualification }\end{array}$} & Masters Degree & 3 \\
\cline { 2 - 3 } & Bachelor Degree & 45 \\
\cline { 2 - 3 } & Diploma and below & 75 \\
\hline \multirow{3}{*}{$\begin{array}{l}\text { Work } \\
\text { Experience }\end{array}$} & More than 15 years & 15 \\
\cline { 2 - 3 } & $10-15$ years & 16 \\
\cline { 2 - 3 } & $5-10$ years & 34 \\
\cline { 2 - 3 } & $<5$ years & 55 \\
\hline
\end{tabular}




\begin{tabular}{|c|l|c|}
\hline \multirow{3}{*}{ Category } & \multicolumn{1}{|c|}{ Classification } & Number of respondents \\
\hline \multirow{4}{*}{ Position } & Chief Engineer/Project Manager & 7 \\
\cline { 2 - 3 } & Proprietor & 14 \\
\cline { 2 - 3 } & Executive/Project Engineer & 26 \\
\cline { 2 - 3 } & Assistant/Junior/Site Engineer & 73 \\
\hline
\end{tabular}

\section{Results and Discussion}

The relative importance index (RII) used by Kometa, Olomolaiye and Harris (1994) and Sambasivan and Soon (2007) was adopted to rank factors based on their affliction on the time overrun in the construction projects. These rankings enable cross-comparison of the importance of the factors as perceived by the respondents working in different organizations at different locations with a wide range of project sizes.

Where

$$
\text { Relative Importance Index (RII) }=\sum W /(A \times N)
$$

$$
\begin{array}{rll}
\Sigma W & = & \begin{array}{l}
\text { Sum of the weighting given to the factor (Weighting is the scale selected by each } \\
\text { respondent for that factor. }
\end{array} \\
A & = & \text { The Highest Weighting option available for that factor. } \\
N & = & \text { Total number of respondents for that factor. }
\end{array}
$$

By using the relation, the factors have been ranked based on the perspectives received from the respondents, which are directly proportional to their adversity, which means those factors having higher RII values are causing a higher impact on the time overrun of the construction projects. The rankings of the different factors are drawn from the overall response received and are compared to find the relation of the effect of factors between two groups, private and clients. Further, the rankings of the factors are made based on the different project sizes for the determination of the factors affecting the time overrun at different project sizes and also to check the relation of these factors at different project size levels.

The perspectives on the different factors received from 120 respondents were ranked using the RII relation as shown in Table 2. The more frequently occurring factors are: (i) Experience of the contractor for the same work with RII of 0.914, (ii) Financial stability of the contractor with RII of 0.914, (iii) Productivity of manpower with RII of 0.879, (iv) System of work award to the lowest bidder with RII of 0.872 and (v) Unfavorable weather conditions with RII of 0.870 . The factors with the higher RII value are ranked at the top, and their effect on the time overrun of the construction projects is also high and vice versa, so the improper monitoring of the contractors by the project management team with an RII of 0.492 ranked last which means it rarely affected compared to the other factors.

Table 2. RII ranks of the factors based on the overall response.

\begin{tabular}{|l|l|c|c|}
\hline \multicolumn{2}{|c|}{ Factors affecting time overrun } & \multirow{2}{*}{ RII } & Rank \\
\hline \multirow{4}{*}{ Project Related } & Complexity of the project & 0.747 & 19 \\
\cline { 2 - 4 } & System of work award to the lowest bidder & 0.872 & 4 \\
\cline { 2 - 4 } & Change in scope, design and other discrepancies & 0.755 & 16 \\
\cline { 2 - 4 } & Penalty imposed for the work delay is inappropriate & 0.572 & 30 \\
\hline \multirow{4}{*}{$\begin{array}{l}\text { Project } \\
\text { Management Related }\end{array}$} & Time taken for decision making & 0.736 & 20 \\
\cline { 2 - 4 } & Suspension of work and delay in payments & 0.722 & 21 \\
\cline { 2 - 4 } & Unrealistic calculation of the project duration & 0.642 & 27 \\
\cline { 2 - 4 } & Change in project management team & 0.713 & 22 \\
\cline { 2 - 4 } & Delay in the review of the work progress & 0.679 & 26 \\
\cline { 2 - 4 } $\begin{array}{l}\text { Contractor } \\
\text { Related }\end{array}$ & Improper monitoring of the contractors involved & 0.492 & 31 \\
\cline { 2 - 4 } & Experience of the contractor for the same work & 0.918 & 1 \\
\cline { 2 - 4 } & Financial stability of the contractor & 0.914 & 2 \\
\cline { 2 - 4 } & Availability of loan and debt system & 0.857 & 6 \\
\cline { 2 - 4 } & Issues related to sub-contracting & 0.692 & 25 \\
\cline { 2 - 4 } & Proper planning in purchase of materials/equipment & 0.855 & 8 \\
\cline { 2 - 4 } & Use of inadequate methods and techniques & 0.855 & 7 \\
\hline \multirow{5}{*}{ Labour Related } & 0.879 & 3 \\
\cline { 2 - 4 } & Productivity of manpower & 0.817 & 12 \\
\cline { 2 - 4 } & Lack of skilled labour & 0.605 & 29 \\
\cline { 2 - 4 } & Lsage of foreign labour & 0.750 & 18 \\
\cline { 2 - 4 } & Eack of skilled operators for the equipment & 0.795 & 13 \\
\hline
\end{tabular}




\begin{tabular}{|l|l|c|c|}
\hline \multicolumn{2}{|c|}{ Factors affecting time overrun } & RII & \multirow{2}{*}{ Rank } \\
\hline \multirow{2}{*}{$\begin{array}{l}\text { Equipment } \\
\text { Related }\end{array}$} & Efficiency of equipment & 0.847 & 10 \\
\cline { 2 - 4 } & Suitability equipment selected for work & 0.751 & 17 \\
\cline { 2 - 4 } Material & Hiring of equipment & 0.640 & 28 \\
\hline Related & Shortage of construction materials & 0.850 & 9 \\
\cline { 2 - 4 } & Issues related to the transportation of the materials & 0.832 & 11 \\
\cline { 2 - 4 } & Price escalation of the construction materials & 0.706 & 23 \\
\hline \multirow{5}{*}{ Others } & Unfavorable weather conditions & 0.870 & 5 \\
\cline { 2 - 4 } & Delay in obtaining clearances & 0.762 & 14 \\
\cline { 2 - 4 } & Unnecessary involvement of external agencies & 0.757 & 15 \\
\cline { 2 - 4 } & Changes in the rules and regulations & 0.693 & 24 \\
\hline
\end{tabular}

The perspectives received from the personals working under the government/client and those working under the private firms were ranked as shown in Table 3. The top 5 factors from the perspectives of both the parties are found to be the same though their rankings differ to one another and they are: (i) Experience of the contractor, (ii) Financial stability of the contractor, (iii) Productivity of the manpower, (iv) System of work award to the lowest bidder and (v) Unfavorable weather condition.

Table 3. Comparison of RII ranks of the factors

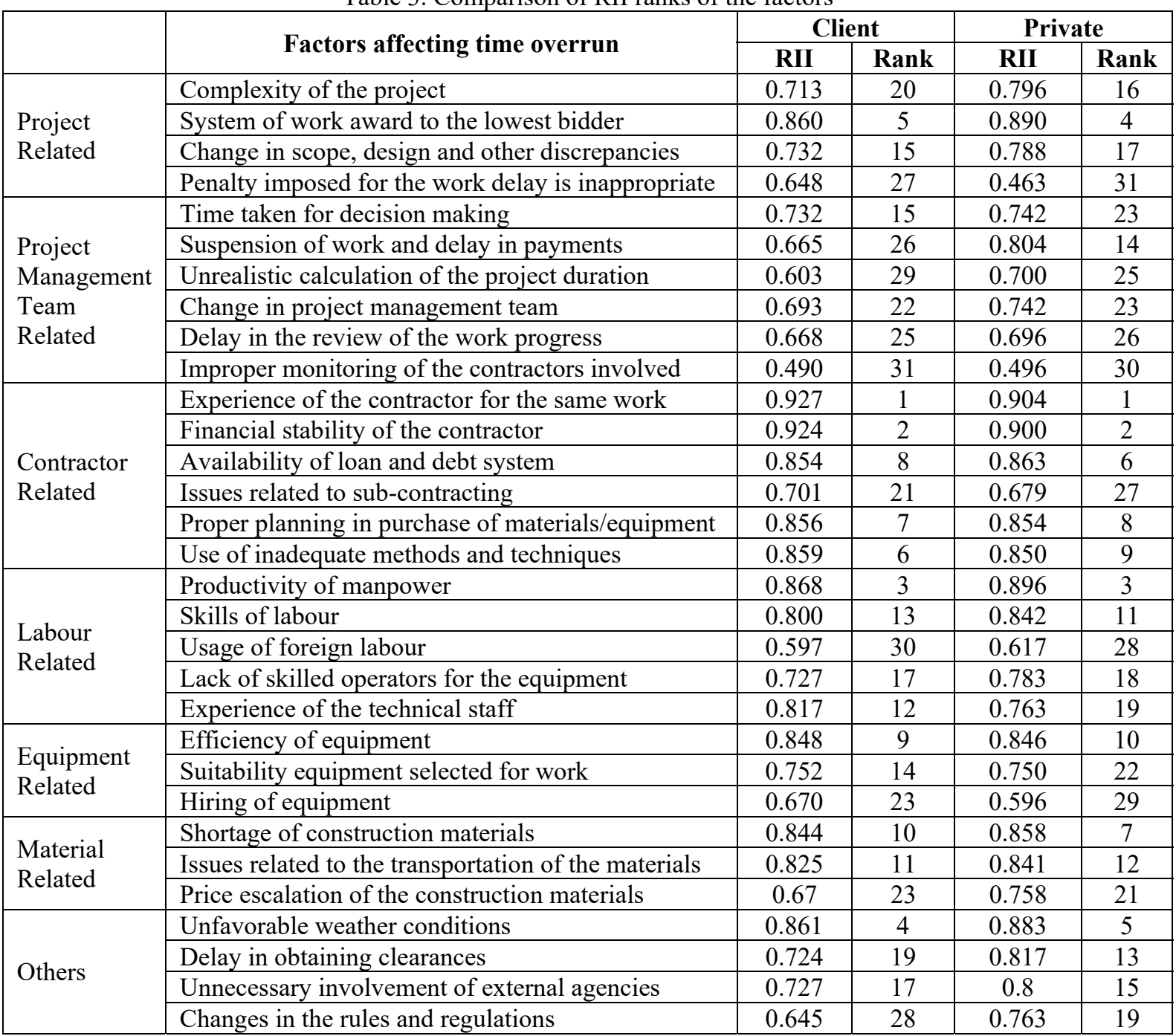

The top 10 factors affecting time overrun in construction projects in Bhutan are shown in Table 4 . Both the groups, i.e. private and government agencies agree to all the top 10 factors though the ranking differed in its order. The top 10 factors as ranked in the response of the personals from the private matched the responses from that of the client/government. The factors in Table 4 are the ones that are occurring more frequently compared to others. 
Table 4. Top 10 factors affecting time overrun in Bhutan

\begin{tabular}{|l|c|c|c|c|c|c|}
\hline \multirow{2}{*}{\multicolumn{1}{c|}{ Factors affecting time overrun }} & \multicolumn{2}{c|}{ Overall } & \multicolumn{2}{c|}{ Client } & \multicolumn{2}{c|}{ Private } \\
\cline { 2 - 7 } & RII & Rank & RII & Rank & RII & Rank \\
\hline Experience of the contractor for the same work & 0.918 & 1 & 0.927 & 1 & 0.904 & 1 \\
\hline Financial stability of the contractor & 0.914 & 2 & 0.924 & 2 & 0.900 & 2 \\
\hline Productivity of manpower & 0.879 & 3 & 0.868 & 3 & 0.896 & 3 \\
\hline System of work award to the lowest bidder & 0.872 & 4 & 0.860 & 5 & 0.890 & 4 \\
\hline Unfavorable weather conditions & 0.870 & 5 & 0.861 & 4 & 0.883 & 5 \\
\hline Availability of loan and debt system & 0.857 & 6 & 0.854 & 8 & 0.863 & 6 \\
\hline Use of inadequate methods and techniques & 0.855 & 7 & 0.859 & 6 & 0.850 & 9 \\
\hline Proper planning in purchase of materials/equipment & 0.855 & 8 & 0.856 & 7 & 0.854 & 8 \\
\hline Shortage of construction materials & 0.850 & 9 & 0.844 & 10 & 0.858 & 7 \\
\hline Efficiency of equipment & 0.847 & 10 & 0.848 & 9 & 0.846 & 10 \\
\hline
\end{tabular}

The data collected are further segregated into different project size and CDB classification. Respondents from the private were classified based on CDB classification and respondents from the clients were classified as per their work supervision. Based on the different project sizes, the factors were again ranked using RII as shown in Table 5. The rank of the factors which is directly proportional to the adversity of the effect on the time overrun is found to be similar across the different project sizes with few differences.

Table 5. Comparison of RII ranks of the factors between different project sizes

\begin{tabular}{|c|c|c|c|c|c|c|}
\hline \multirow{2}{*}{ Factors affecting time overrun } & \multicolumn{2}{|c|}{ Large } & \multicolumn{2}{|c|}{ Medium } & \multicolumn{2}{|c|}{ Small } \\
\hline & RII & Rank & RII & Rank & RII & Rank \\
\hline Complexity of the project & 0.745 & 19 & 0.828 & 9 & 0.667 & 26 \\
\hline System of work award to the lowest bidder & 0.930 & 2 & 0.859 & 4 & 0.890 & 6 \\
\hline Change in scope, design and other discrepancies & 0.765 & 15 & 0.779 & 15 & 0.711 & 22 \\
\hline Penalty imposed for the work delay is inappropriate & 0.594 & 30 & 0.421 & 31 & 0.689 & 24 \\
\hline Time taken for decision making & 0.748 & 17 & 0.690 & 22 & 0.763 & 17 \\
\hline Suspension of work and delay in payments & 0.690 & 25 & 0.779 & 15 & 0.733 & 21 \\
\hline Unrealistic calculation of the project duration & 0.642 & 27 & 0.628 & 26 & 0.659 & 29 \\
\hline Change in project management team & 0.719 & 22 & 0.655 & 24 & 0.763 & 17 \\
\hline Delay in the review of the work progress & 0.687 & 26 & 0.641 & 25 & 0.704 & 23 \\
\hline Improper monitoring of the contractors involved & 0.465 & 31 & 0.490 & 30 & 0.556 & 31 \\
\hline Experience of the contractor for the same work & 0.932 & 1 & 0.890 & 2 & 0.952 & 1 \\
\hline Financial stability of the contractor & 0.923 & 3 & 0.910 & 1 & 0.944 & 2 \\
\hline Availability of loan and debt system & 0.856 & 7 & 0.855 & 5 & 0.840 & 7 \\
\hline Issues related to sub-contracting & 0.694 & 24 & 0.628 & 26 & 0.776 & 13 \\
\hline Purchase of materials/equipment & 0.861 & 6 & 0.820 & 11 & 0.912 & 4 \\
\hline Use of inadequate methods and techniques & 0.839 & 10 & 0.848 & 7 & 0.936 & 3 \\
\hline Productivity of manpower & 0.887 & 5 & 0.862 & 3 & 0.912 & 4 \\
\hline Skills of labour & 0.826 & 12 & 0.814 & 12 & 0.824 & 10 \\
\hline Usage of foreign labour & 0.616 & 29 & 0.579 & 29 & 0.608 & 30 \\
\hline Lack of skilled operators for the equipment & 0.726 & 20 & 0.793 & 14 & 0.776 & 13 \\
\hline Experience of the technical staffs & 0.829 & 11 & 0.759 & 18 & 0.776 & 13 \\
\hline Efficiency of equipment & 0.855 & 8 & 0.821 & 10 & 0.800 & 11 \\
\hline Suitability equipment selected for work & 0.755 & 16 & 0.752 & 20 & 0.760 & 19 \\
\hline Hiring of equipment & 0.629 & 28 & 0.600 & 28 & 0.670 & 25 \\
\hline Shortage of construction materials & 0.855 & 8 & 0.834 & 8 & 0.837 & 9 \\
\hline Issues related to the transportation of materials & 0.784 & 13 & 0.800 & 13 & 0.760 & 19 \\
\hline Price escalation of the construction materials & 0.703 & 23 & 0.759 & 18 & 0.664 & 27 \\
\hline Unfavourable weather conditions & 0.900 & 4 & 0.850 & 6 & 0.840 & 7 \\
\hline Delay in obtaining clearances & 0.777 & 14 & 0.738 & 21 & 0.768 & 16 \\
\hline Unnecessary involvement of ext & 0.748 & 17 & 0.766 & 17 & 0.784 & 12 \\
\hline Changes in the rules and regulations & 0.723 & 21 & 0.662 & 23 & 0.664 & 27 \\
\hline
\end{tabular}

The top 10 factors leading to the project time overrun in Bhutan are found to be (i) Experience of the

Contractor for the same work; (ii) Financial stability of the contractor; (iii) Productivity of the manpower; (iv) System of the work award to the lowest bidder; (v) Unfavorable weather conditions; (vi) Availability of loan and debt system; (vii) Use of inadequate method and techniques in the work execution; (viii) Improper planning in the procurement of materials; (ix) Shortage of construction materials, and (x) Efficiency of the equipment. The overall 
result shows that a contractor plays a vital role in the timely completion of the projects as most of the leading factors causing time overrun are directly related to them.

The result of this study is similar to the findings of the other studies. A study conducted by Tesfa (2016) on the time overrun in road construction in Ethiopia found that factors such as contractors financial problems, inadequate contractor experience, low productivity of the labour, improper planning, and supply of materials are the leading causes of time overrun. Similarly study on the time overrun in the construction projects in Malaysia done by Memon (2014) and the group also found the factors causing the time overrun in the construction projects similar to the present study.

\section{Conclusions}

An online survey was carried out to assess the top 10 factors causing time overrun in the construction projects in Bhutan using the relative importance index method on the online responses. The significant factor affecting the construction time attributes to similar work experience of the contractor while the least is the improper monitoring of the contractors by the client. The results are same for both, the contractors and the clients. The rank of the factors which is directly proportional to time overrun is found to be similar across the different project size.

Based on the findings of this research, it is recommended that during the selection of contractors, experience in similar works are assessed with greater weights during the evaluations prior to contract award. Furthermore, the finding infers that the system of awarding the work to the lowest bid is also one of the top contributing factors to the time overrun. Conversely, as the least factor attributing to time overruns is improper monitoring of the contractors by the client as per the findings, the weights during the evaluation phase is recommended to be prioritized.

As this research was focused on the performance of the contractors and clients during the implementation of the project, future works could focus on assessment of provision of construction time for projects by the clients with focus on one type of construction, or contractor type unlike in this study where the survey was carried out broadly over all contractor types - small, medium and large and for every type of civil works. It is also recommended to use other type of survey methodologies such as face to face interviews to improve the responses. Further, similar to this study, future research may be carried out to assess the cost overrun as it is closely related to time overrun.

\section{References}

Kaming, P., Olomolaiye, P., Holt, G., \& Harris, F. (1997). Factors influencing construction time and cost overruns on high-rise projects in Indonesia. Construction Management and Economics, 15(1), 83-94.

CDB. (2018). Annual Report 2017-2018. Costruction Development Board, thimphu, Bhutan.

CDB. (2019, January 5). An insight into the construction industry of Bhutan: Part I. Kuenselonline. Retrieved from Kuenselonline: https://kuenselonline.com/an-insight-into-the-construction-industry-of-bhutan-part-i/

Doloi, H., Sawhney, A., Iyer, K., \& Rentala, S. (2012). Analysing factors affecting delays in Indian construction projects. International Journal of Project Management, 30(4), 479-489.

Faridi, A. S., \& El-Sayegh, S. M. (2006). Significant factors causing delay in the UAE construction industry. Construction Management and Economics, 24(11), 1167-1176.

Herrera, R., Sánchez, O., Castañeda, K., \& Porras, H. (2020). Cost overrun causative factors in road infrastructure projects: A frequency and importance analysis. Applied Sciences (Switzerland), 10(6).

Kometa, S., Olomolaiye, P., \& Harris, F. (1994). Attributes of UK construction clients influencing project consultants' performance. Construction Management and Economics, 12(5).

Kuensel. (2017, July 15). The cost of delayed projects. Retrieved from Kuenselonline: https://kuenselonline.com/the-cost-of-delayed-projects/

Memon, A. (2014). Contractor perspective on time overrun factors in Malaysian Construction projecs. International Journal of Science, Environment and Technology, 3(3), 1184-1192.

Mohammed, K. (2012). Causes of Delay in Nigeria Construction Industry. Interdisciplinary Journal of Contemporary Research in Business, 2(4), 785-794.

Murali, S., \& Kumar, S. (2019). Factors affecting overruns construction time and cost: A case study. International Journal of Recent Technology and Engineering, 7(6), 284-288.

NSB. (2018). Statistical Yearbook of Bhutan 2018. Royal Government of Bhutan. National Statistics Bureau, Royal Government of Bhutan, Thimphu, Bhutan.

Ozcan-Deniz, G., Zhu, Y., \& Ceron, V. (2012). Time, cost, and environmental impact analysis on construction operation optimization using genetic algorithms. Journal of Management in Engineering, 23(3), 265-272.

Pai, S., \& Bharat, J. (2013). Analysis Of Critical Causes Of Delays In Indian Infrastructure Projects. International Journal of Innovative Research \& Development, 2(3), 251-263.

Sambasivan, M., \& Soon, Y. (2007). Causes and effects of delays in Malaysian construction industry. International Journal of Project Management, 25(5). 
Subramani, S., Prabhu, G., \& Dey, S. (2016). Identifying the factors causing time overrun in construction projects in Chennai and suggesting for possible solutions. International Journal of Civil Engineering and Technology, $7(6), 660-668$.

Tesfa, S. Y. (2016). Analysis of Factors Contributing to Time Overruns on Road Construction Projects under Addis Ababa City Administration. International Journal of Science and Research, 5(7), 2181-2187.

Ubani, E., Okorocha, K., \& Emeribe, S. (2013). Analysis of factors influencing time and cost overruns on construction projects in South Eastern Nigeria. International Journal of Management Sciences and Business Research, 2(2), 73-84. 